\title{
Fine Mutational Analysis of 2B8 and 3H7 Tag Epitopes with Corresponding Specific Monoclonal Antibodies
}

\author{
Tae-Lim Kim ${ }^{1,2}$, Man-Ho Cho ${ }^{1,2}$, Kanidta Sangsawang', and Seong Hee Bhoo, *
}

\begin{abstract}
Bacteriophytochromes are phytochrome-like light-sensing photoreceptors that use biliverdin as a chromophore. To study the biochemical properties of the Deinococcus radiodurans bacteriophytochrome (DrBphP) protein, two antiDrBphP mouse monoclonal antibodies (2B8 and $3 \mathrm{H7}$ ) were generated. Their specific epitopes were identified in our previous report. We present here fine epitope mapping of these two antibodies by using truncation and substitution of original epitope sequences in order to identify minimized epitope peptides. The previously reported original epitope sequences for $2 \mathrm{~B} 8$ and $3 \mathrm{H} 7$ were truncated from both sides. Our analysis showed that the minimal peptide sequence lengths for $2 \mathrm{~B} 8$ and $3 \mathrm{H} 7$ antibodies were nine amino acids (RDPLPFFPP) and six amino acids (PGEIEE), respectively. We further characterized these peptides in order to investigate their reactivity after single deletion and single substitution of the original peptides. We found that single-substituted $2 B 8$ epitope (RDPLPAFPP) and dualsubstituted 3 H7 epitope (PGEIAD) showed significantly increased reactivity. These two antibodies with high reactivity for the short modified peptide sequences are valueble for developing new peptide tags for protein research.
\end{abstract}

\section{INTRODUCTION}

Monoclonal antibodies (mAbs) are biologically and biochemically important proteins that have greatly advanced research into protein function, clinical therapies and diagnosis (Chu and Englund, 2013; de Mello et al., 2013; Lopez-Requena et al., 2012; Martin-Mateos, 2007; Simmons et al., 2007; Sun et al., 2007). Although recent technological advances have enabled production of new monoclonal antibodies for specific target proteins, the process is still time-consuming and expensive. For these reasons, many researchers use an epitope tagging system as a

\footnotetext{
${ }^{1}$ Graduate School of Biotechnology, Kyung Hee University, Yongin 17104 , Korea, ${ }^{2}$ These authors are contributed equally to this work. *Correspondence: shbhoo@khu.ac.kr
}

Received 7 October, 2015; revised 15 April, 2016; accepted 22 April, 2016; published online 3 May, 2016

Keywords: 2B8 monoclonal antibody, 3H7 monoclonal antibody, DrBphP protein, epitope mapping, tag convenient and easy biochemical methodology when specific antibodies for the protein of interest are not readily available (Brizzard, 2008; Nygren et al., 1994; Terpe, 2003). Recently, epitope tagging has been widely used for detection, localization and purification of interesting recombinant proteins. An epitope tag peptide sequence is usually fused to the amino or carboxyl terminus or sometimes inserted within a protein of interest. The presence of a fused target protein is assessed with an already available epitope-tag specific antibody (Jarvik and Telmer, 1998; Waugh, 2005). The most commonly used epitope tag peptides are polyhistidine-tag (His-tag), polyarginine-tag, FLAGtag, Strep-tag, c-Myc-tag, HA-tag, maltose binding protein (MBP), and glutathione-S-transferase (GST) (Bedouelle and Duplay, 1988; Evan et al., 1985; Field et al., 1988; Hopp et al., 1988; Kolodziej and Young, 1991; Neill et al., 1997; Porath et al., 1975; Schmidt and Skerra, 1993; Smith and Johnson, 1988; Smith et al., 1984). Short peptide tags are generally presumed to have no effect on the biological functions of fused proteins and therefore do not need to be removed. Larger epitope tags such as MBP and GST could enhance the solubility of target proteins (Sachdev and Chirgwin, 1999). Depending on their placement, fused epitope tags occasionally interfere with the structure, biological activity and/or crystallization of fused proteins (Bucher et al., 2002; Chant et al., 2005; Goel et al., 2000; Woestenenk et al., 2004; Wu and Filutowicz, 1999).

Therefore, researchers must consider the biochemical characteristics and expression host of target proteins when choosing epitope tags because tag-fused recombinant protein expression and stability depend on the nature of both proteins and hosts. The reactivity of tag-fused target proteins with the corresponding tag-specific monoclonal antibodies varies according to immunodetection method, such as Western blotting, immunofluorescence staining, immunoprecipitation, or flow cytometry. His-tag fused target proteins such as Nla protease of papaya ringspot virus $W$ type (WNpro), HC-Pro of zucchini yellow mosaic virus (ZHC), house dust mite chimeric allergen (Dp25), and nucleocapsid protein of watermelon silver mottle virus (WNP) have expression problems in bacterial or plant expression systems even though other tags don not have problems in the same expression system (Cheng et al., 2013). Dual tags of MBP with His-tag or Arg-tag used to enhance purification efficiency and solubility of the MBP fusion protein (Routzahn and Waugh, 2002). The FLAG M2 antibody showed non-specific Western blot bands in Brassica juncea Indian mustard plant, especially on shoot and leaf tissue, 
suggesting that FLAG-tag is not a suitable expression tag in this plant (Gasic and Korban, 2005). Compared with the traditional FLAG M2 antibody, a newly developed L5 antibody for FLAG-tag has enhanced reactivity for modified FLAG-tagged proteins. Furthermore, the L5 antibody showed significantly increased reactivity over a FLAG-tag sequence containing the new OLLAS-tag (Park et al., 2008).

To maintain the biochemical properties of tag-fused target proteins, tags must not interfere with biochemical properties of target proteins such as surface net charges, hydrophobicity, and side chain reactivity. Smaller peptides are advantageous for minimizing side effects over the fused target proteins. However, smaller peptides have the disadvantage of increasing reactivity with non-specific peptide-containing proteins.

In our previous report, $2 \mathrm{~B} 8$ and $3 \mathrm{H} 7$ peptide tags were identified as parts of a $D$. radiodurans bacteriophytochrome (DrB$\mathrm{phP}$ ), the phytochrome-like photoreceptor designated as bacteriophytochromes (Bhoo et al., 2001; Davis et al., 1999). We originally generated five DrBphP-specific monoclonal antibodies, including $2 \mathrm{~B} 8$ and $3 \mathrm{H} 7$, and mapped their epitope positions for use in structural and biochemical studies of bacteriophytochromes (Kim et al., 2014). In the present study, we performed mutational mapping including internal deletion and internal substitution of two epitope tag peptides reacted with 2B8 and $3 \mathrm{H} 7$ antibodies for ELISA and Western blot analysis. The results indicated various critical residues for reactivity with both monoclonal antibodies. In particular, a single-substituted 2B8 epitope tag (RDPLPAFPP) and dual-substituted $3 \mathrm{H} 7$ epitope tag (PGEIAD) showed significantly increased reactivity. These new mutated epitope tags raise the possibility of generating new epitope tags and their specific antibodies.

\section{MATERIALS AND METHODS}

\section{Preparation of truncated DrBphP peptide constructs}

Full-length DrBphP DNA was used as a template for the construction of all DrBphP deletion mutants. DNA constructs of short peptide fragments (1-12 aa, 3-12 aa, 3-11 aa, 3-10 aa, 411 aa, 481-495 aa, 481-490 aa, 485-495 aa, 485-494 aa, 485493 aa, 485-492 aa, 485-491 aa, 485-490 aa, 485-489 aa and 486-495 aa), Ala substitutions (3-11-R3A, 3-11-D4A, 3-11-P5A, 3-11-L6A, 3-11-P7A, 3-11-F8A, 3-11-F9A, 3-11-P10A, 3-11P11A, 485-490-P485A, 485-490-G486A, 485-490-E487A, 485490-1488A, 485-490-E489A and 485-490-E490A), single or dual substitutions (3-11-R3K, 3-11-D4E, 3-11-D4N, 3-11-L6I, 311-L6V, 3-11-F8Y, 3-11-F9Y, 3-11-D4E-F8A, 3-11-D4E-F8Y, 485-490-E487D, 485-490-E487Q, 485-490-I488L, 485-490I488V, 485-490-E489D, 485-490-E489Q, 485-490-E490D, 485-490-E490Q and 485-490-E489A-E490D), and single deletions (3-11- $\Delta \mathrm{D} 4,3-11-\Delta \mathrm{P} 5,3-11-\Delta \mathrm{L} 6,3-11-\Delta \mathrm{P} 7,3-11-\Delta \mathrm{F} 8$, 311- $\Delta \mathrm{P} 10, \quad 485-490-\Delta \mathrm{G} 486, \quad 485-490-\Delta \mathrm{E} 487, \quad 485-490-\Delta \mathrm{l} 488$ and $485-490-\Delta E 489$ ) were generated by $P C R$ and were cloned into the pGEX4T1 vector, which contains GST as a fusion protein. Supplementary Table 1 shows all primers used for DNA construction.

\section{Expression and purification of epitope-tagged proteins}

DNA constructs of epitope-tagged proteins were cloned into pGEX4T1 vectors and expressed in Escherichia coli BL21 cells. The cells grown at $25^{\circ} \mathrm{C}$ were induced to express recombinant proteins with $0.5 \mathrm{mM}$ IPTG. After $6 \mathrm{~h}$ protein induction, cells were collected by centrifugation. The harvested cells were resuspended in phosphate-buffered saline (PBS, $137 \mathrm{mM} \mathrm{NaCl}$, and $2.7 \mathrm{mM} \mathrm{KCl}, 10 \mathrm{mM} \mathrm{Na}_{2} \mathrm{HPO}_{4}, 2 \mathrm{mM} \mathrm{KH}_{2} \mathrm{PO}_{4}, \mathrm{pH}$ 7.4).
Resuspended cells were lysed by sonication on ice. The cell lysate was centrifuged at $16,000 \mathrm{~g}$ for $10 \mathrm{~min}$ at $4^{\circ} \mathrm{C}$. Clarified total protein solution was then subjected to a GST-resin affinity column purification system (GE Healthcare, USA) according to the manufacturer's instructions. Target proteins were eluted in a Tris buffer ( $50 \mathrm{mM}$ Tris- $\mathrm{HCl}, \mathrm{pH}$ 8.0) containing $20 \mathrm{mM}$ glutathione. The purified epitope-tagged target proteins were stored at $-70^{\circ} \mathrm{C}$ for later use.

\section{SDS-PAGE and Western blot}

Protein samples were mixed with SDS sample buffer (125 mM Tris-HCl, pH 6.8; 4\% (w/v) SDS; 0.005\% (w/v) bromophenol blue; $20 \%$ (v/v) glycerol; $5 \%$ (v/v) $\beta$-mercaptoethanol). SDSPAGE was performed with $10 \%$ acrylamide gels in Tris running buffer (25mM Tris pH 8.3, 0.1\% (v/v) SDS, 250 mM glycine) using a Hofer ${ }^{\mathrm{TM}}$ Dual Gel Caster (GE Healthcare, USA) at 20 $\mathrm{mA}$ for $90 \mathrm{~min}$. After SDS-PAGE, separated proteins were stained with Coomassie brilliant blue R-250 (Sigma-Aldrich, USA). Proteins separated on $10 \%$ SDS-PAGE were also transferred to a polyvinylidene difluoride membrane (Invitrogen, USA) for Western blot analysis. Anti-GST antibody (GST Ab-1, Neo Markers, USA) and two epitope-specific monoclonal antibodies (2B8 and $3 \mathrm{H} 7$ ) were diluted 2000 -fold in $5 \%(\mathrm{w} / \mathrm{v})$ skim milk in Tris-buffered saline (TBS) and then used to detect GST and epitope-tagged GST proteins. Horseradish peroxidase (HRP)-conjugated anti-mouse IgG was diluted 10,000-fold in $5 \%(\mathrm{w} / \mathrm{v})$ skim milk in TBS and used as a secondary antibody. Western blot signals were detected by chemiluminescence using an ECL reaction (GE Healthcare, USA).

\section{Identification of epitopes by indirect ELISA}

Ninety-six-well microtiter plates (Nunc Maxisorp) were coated with $1 \mu \mathrm{g} / \mathrm{ml}$ of purified proteins in $0.05 \mathrm{M}$ carbonate buffer $(\mathrm{pH}$ 9.6, $100 \mu \mathrm{l} /$ well) at $4^{\circ} \mathrm{C}$ overnight and blocked with $5 \%$ skim milk for $1 \mathrm{~h}$ at room temperature. After washing three times with PBS containing $0.1 \%$ Tween-20 (PBST), 2B8 and 3H7 antibodies (diluted 20,000-fold in 5\% (w/v) skim milk in PBST) were added into the wells and incubated at room temperature for $2 \mathrm{~h}$. After incubation, plates were washed three times with PBST and incubated with secondary antibody (HRP-conjugated goat anti-mouse $\operatorname{lgG}$ ) at room temperature for $1 \mathrm{~h}$. After three rinses with PBST, color was developed with $100 \mu$ l of TMB One Component HRP Microwell Substrate (SurModics BioFX, USA). The color reaction was stopped with $2 \mathrm{M} \mathrm{H}_{2} \mathrm{SO}_{4}$. Absorbance was measured at $450 \mathrm{~nm}$ using a microplate reader. All assays were performed three times and an average value was used for analysis.

\section{RESULTS}

Mapping of optimal epitope sequences for 2B8 and $3 \mathrm{H7}$ mAbs

To map optimal epitope sequences for 2B8 and $3 \mathrm{H} 7$ antibodies, several truncated peptides were expressed in E. coli and their reactivity was analyzed by Western blot and ELISA. Truncated peptides with deletions at either side of the original sequence were produced as a form of GST fusion proteins. As shown in Fig. $1 \mathrm{~A}$, the minimal peptide required for the $2 \mathrm{~B} 8$ antibody was ${ }^{3}$ RDPLPFFPP ${ }^{11}$. The minimal peptide required for the $3 \mathrm{H} 7$ antibody was ${ }^{485} \mathrm{PGEIEE}^{490}$ (Fig. 1B). Therefore, the nineresidue epitope (3-11) for 2B8 and the six-residue epitope (485490) for $3 \mathrm{H} 7$ were essential for epitope-antibody reactions. These short peptides are considered good candidates as valuable epitope tags. Biochemical characterizations were further 
A
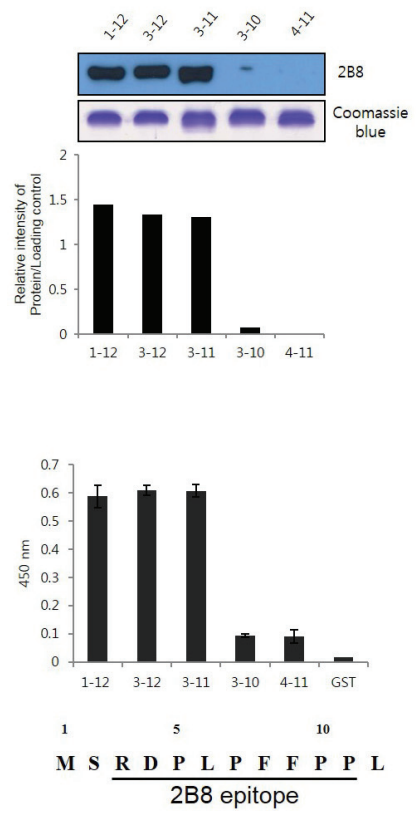

B
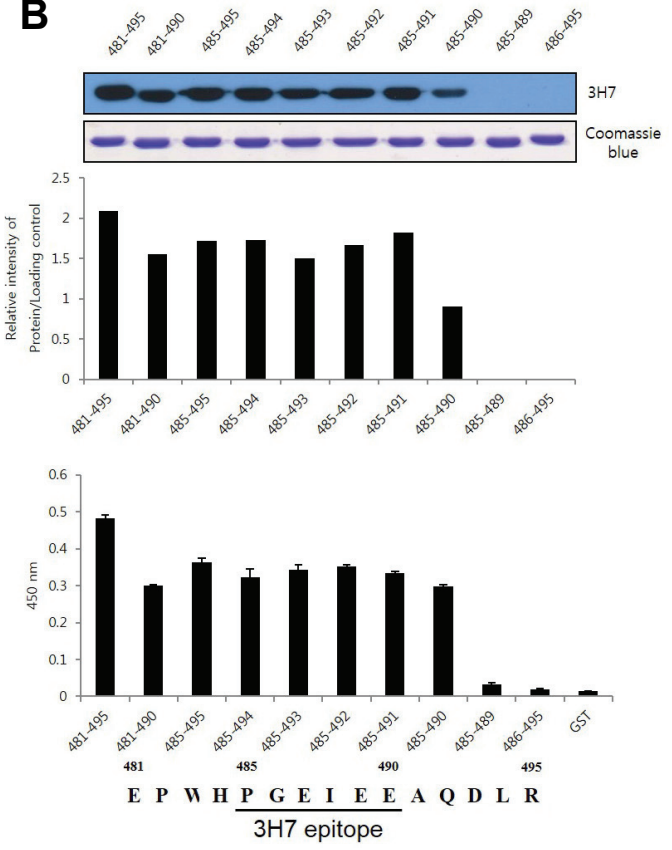

Fig. 1. Fragment mapping of $2 \mathrm{~B} 8$ and 3H7 epitopes by ELISA and Western blot analysis. Epitope-containing peptides with different lengths were expressed with GST protein as a fusion partner. Purified fusion proteins were tested by ELISA probed with 2B8 and $3 \mathrm{H} 7$ antibodies. GST protein was used as a control protein. (A) ELISA and Western blot analyses demonstrated GST fusion proteins containing 1-12, 3-12, 3-11, 3-10, and 4-11 amino acid regions of DrBphP for the 2B8 antibody. (B) ELISA and Western blot analyses revealed GST fusion proteins containing 481-495, 481490 , 485-495, 485-494, 485-493, 485492, 485-491, 485-490, 485-489, and 486-495 amino acid regions of DrBphP for the $3 \mathrm{H} 7$ antibody. Upper and lower panels show the results of Western blot and ELISA, respectively.
A
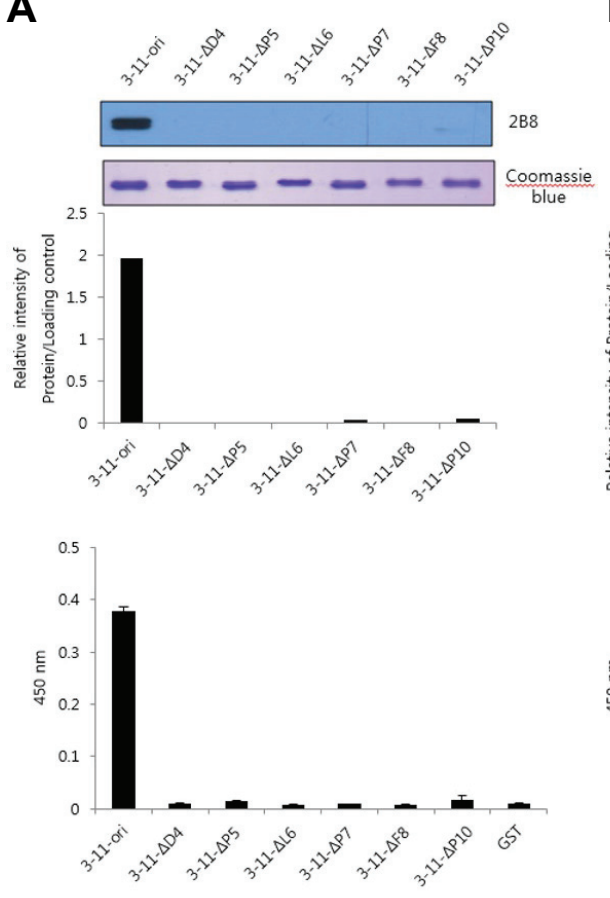

B
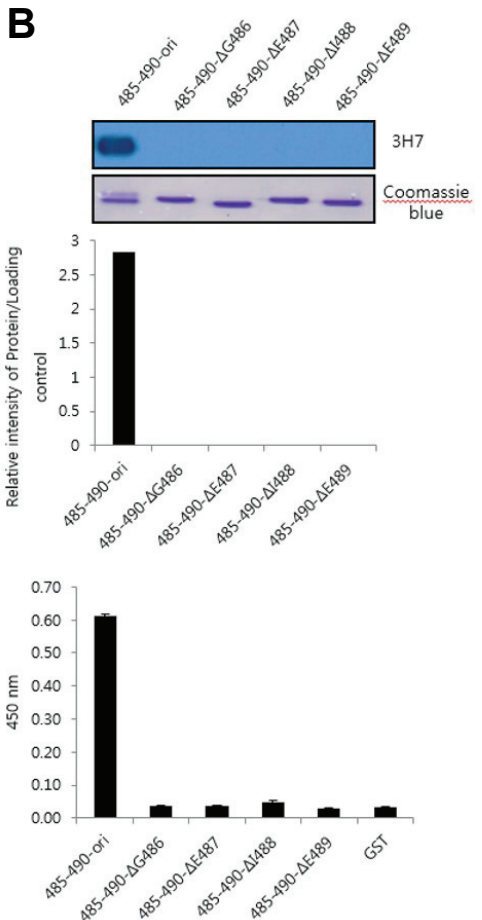

Fig. 2. ELISA and Western blot analyses of single internal deletion mutants of 2B8 and $3 \mathrm{H} 7$ epitopes. Internal deletion mutants of 2B8 and 3H7 epitopes fused with GST protein were produced and subjected to Western blot analysis and ELISA. (A) Original 2B8 epitope (3-11), mutated epitopes (3-11- $\Delta \mathrm{D} 4,3-11-\Delta \mathrm{P} 5,3-11-$ $\Delta \mathrm{L} 6,3-11-\Delta \mathrm{P} 7,3-11-\Delta \mathrm{F} 8$, and 3-11$\triangle \mathrm{P} 10$ ), and GST control. (B) Original $3 \mathrm{H} 7$ epitope (485-490), mutated epitopes (485-490- $\Delta \mathrm{G} 486$, 485-490- $\Delta \mathrm{E} 487$, 485$490-\Delta \mid 488$ and $485-490-\Delta \mathrm{E} 489)$, and GST control. Upper and lower panels show the results of Western blot and ELISA, respectively. required to develop of these peptides as efficient epitope tags. To identify whether shortened epitopes can react with antibodies, a series of single internal deletion mutants of epitopes were generated from the original $2 \mathrm{~B} 8$ and $3 \mathrm{H} 7$ sequences. Singledeletion mutants did not react with their respective antibodies (Fig. 2). The single-deletion 2B8 and 3H7 epitopes resulted in complete loss of response. These results confirmed that the nine-amino acid epitope for 2B8 and the six-amino acid epitope for $3 \mathrm{H} 7$ are minimally required for responses with significant reactivity.

\section{Substitution mutation analysis of $2 \mathrm{~B} 8$ and $3 \mathrm{H} 7$ epitopes}

To identify the role of each amino acid in epitope-antibody reactions, every residue of the $2 \mathrm{~B} 8$ and $3 \mathrm{H} 7$ original sequences 
A
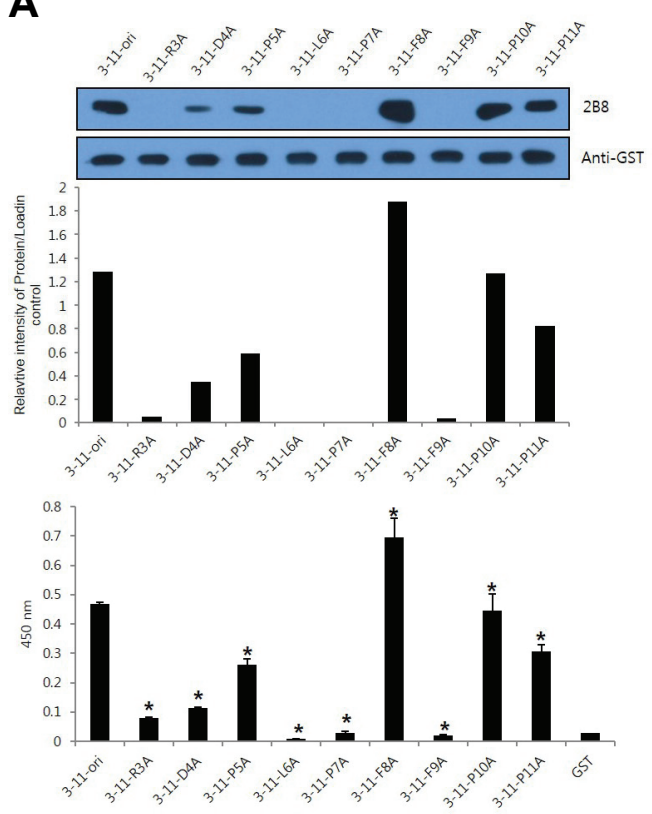
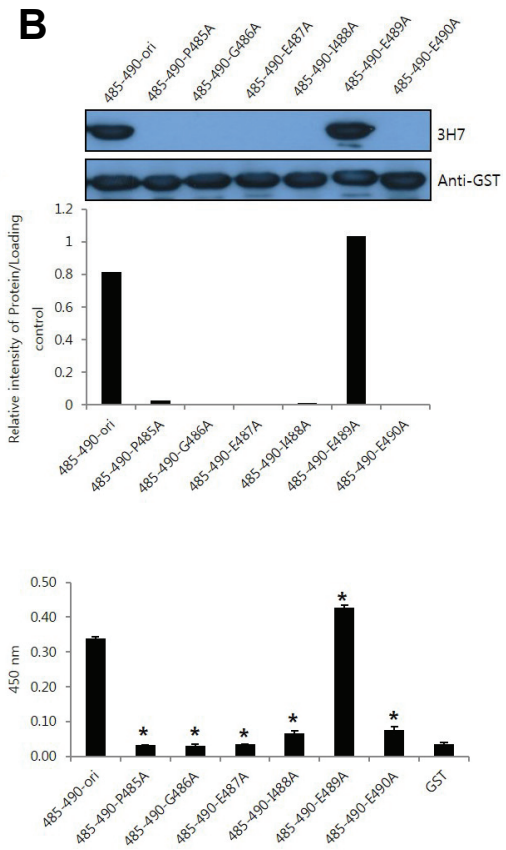

Fig. 3. ELISA and Western blot analyses of single Ala substitutions of 2B8 and $3 \mathrm{H} 7$ epitopes. Substitution mutants of $2 \mathrm{~B} 8$ and $3 \mathrm{H} 7$ epitopes with Ala were produced as GST fusion proteins and subjected to Western blot analysis and ELISA. (A) Original 2B8 epitope (3-11), mutated epitopes (3-11-R3A, 3-11-D4A, 3-11-P5A, 3-11-L6A, 3-11-P7A, 3-11F8A, 3-11-F9A, 3-11-P10A, and 3-11$\mathrm{P} 11 \mathrm{~A}$ ), and GST control. (B) Original $3 \mathrm{H} 7$ epitope (485-490), mutated epitopes (485-490-P485A, 485-490-G486A, 485490-E487A, 485-490-I488A, 485-490E489A, and 485-490-E490A), and GST control. Upper and lower panels show the results of Western blot and ELISA, respectively. Asterisks indicate significant differences ( $p<0.05, t$-test) between mutant and original epitopes.
A
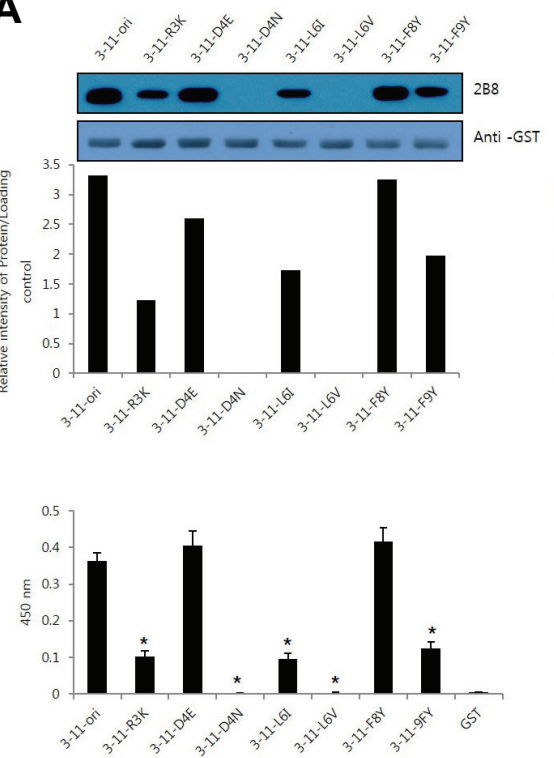

B
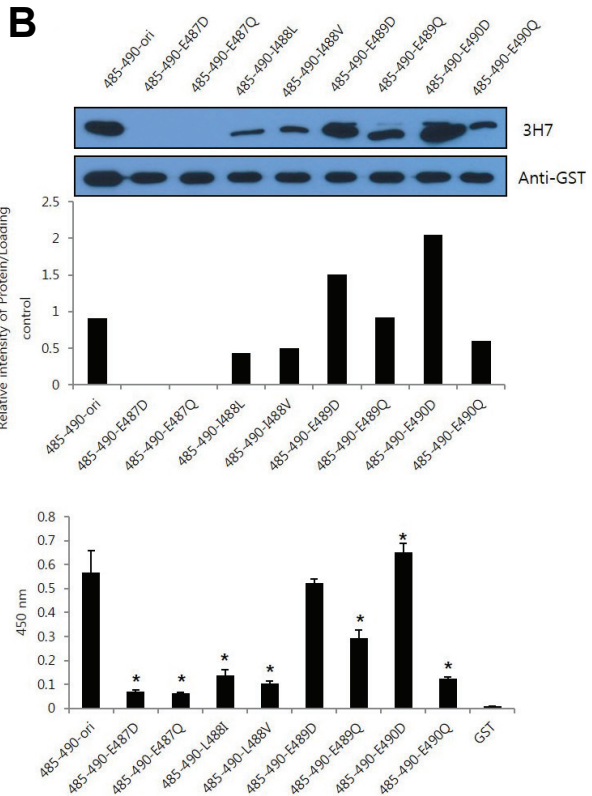

Fig. 4. ELISA and Western blot analyses of single substitutions of 2B8 and $3 \mathrm{H} 7$ epitopes. Substitution mutants of 2B8 and $3 \mathrm{H} 7$ epitopes with similar or neutral amino acid residues were produced as GST fusion proteins and subjected to Western blot analysis and ELISA. (A) Original 2B8 epitope (3-11), mutated epitopes (3-11-R3K, 3-11-D4E, 3-11-D4N, 3-11-L6I, 3-11-L6V, 3-11F8Y, and 3-11-F9Y), and GST control. (B) Original 3H7 epitope (485-490), mutated epitopes (485-490-E487D, 485490-E487Q, 485-490-I488L, 485-490I488V, 485-490-E489D, 485-490-E489Q, 485-490-E490D, and 485-490-E490Q), and GST control. Upper and lower panels show the results of Western blot and ELISA, respectively. Asterisks indicate significant differences $(p<0.05, t$-test) between mutant and original epitopes. was mutated into Ala and analyzed for reactivity with the corresponding antibody. Five (residue numbers 3, 4, 6, 7 and 9) Ala mutations in the 2B8 epitope showed severely decreased responses (Fig. 3A), suggesting that these residues are important for antibody recognition. The P5A, P10A, and P11A mutations showed almost no effect or slightly decreased reactivity compared to the original sequence. With the $3 \mathrm{H} 7$ sequence, all Ala mutations except E489A abolished the response to antibody (Fig. 3B). Interestingly, the single mutations of F8A for 2B8 and E489A for $3 \mathrm{H} 7$ showed significantly increased responses for their specific antibodies (Fig. 3).

Ala substitution mutations indicated that $\mathrm{F} 8, \mathrm{P} 10$, and $\mathrm{P} 11$ for the 2B8 epitope and $\mathrm{E} 489$ for the $3 \mathrm{H} 7$ epitope were not essential for reactivity. To determine the effects of side chains on reactivity, side chains of the 2B8 epitope (except for Pro residues) and $3 \mathrm{H} 7$ epitope (except for Glu and lle residues) were changed into various amino acids. As shown in Fig. 4A, D4E and F8Y mutants showed no significant decrease in reactivity, whereas mutations of the other residues in the 2B8 epitope showed severe decreases in reactivity even though the mutat- 
A

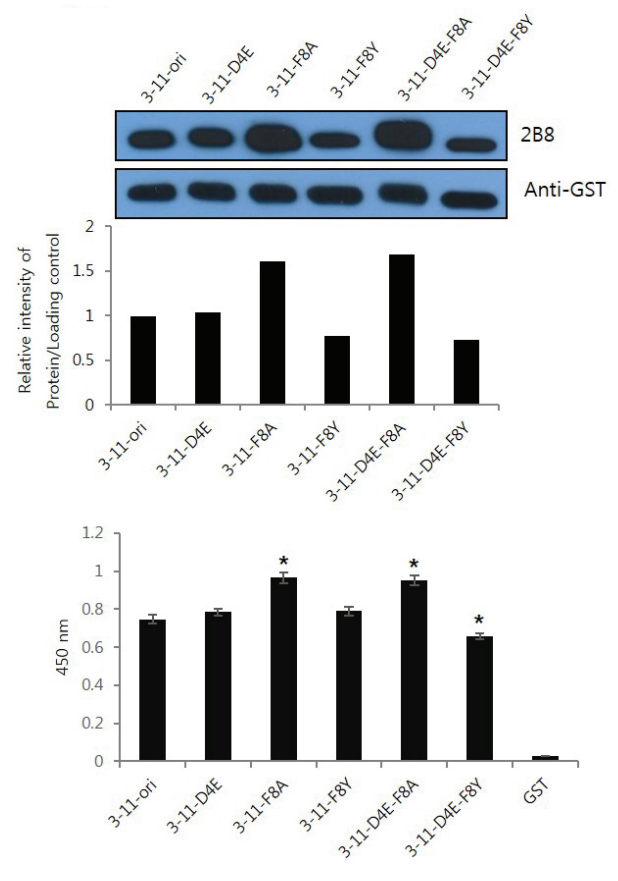

B
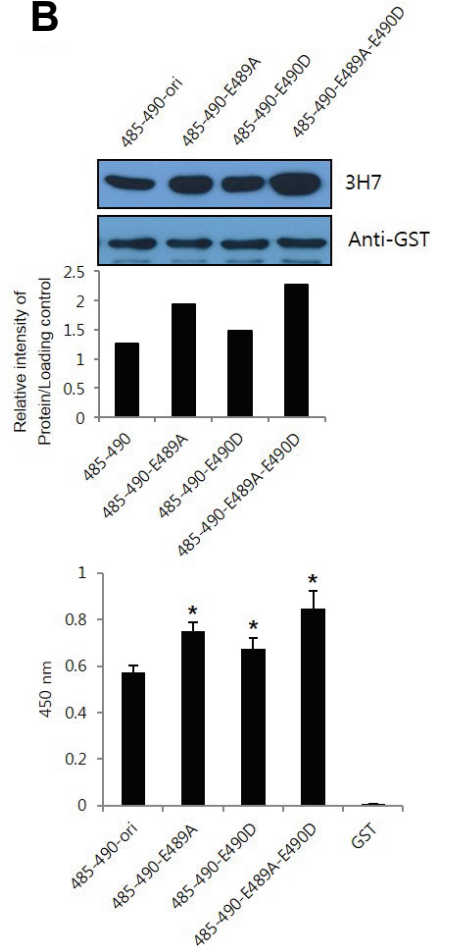

Fig. 5. ELISA and Western blot analyses of single or dual internal substitutions in 2B8 and $3 \mathrm{H} 7$ epitopes. Single substituted epitopes with higher response than originals were selected and combined to produce dual substituted epitopes that were tested to determine whether combined dual substitution result in additive response. (A) Original 2B8 epitope (3-11), mutated epitopes (3-11-D4E, 3-11-F8A, 311-F8Y, 3-11-D4E-F8A, and 3-11-D4EF8Y), and GST control. (B) Original $3 \mathrm{H} 7$ epitope (485-490), mutated epitopes (485490-E489A, 485-490-E490D, and 485490-E489A-E489D), and GST control. Upper and lower panels show the results of Western blot and ELISA, respectively. Asterisks indicate significant differences ( $p<0.05$, $t$-test) between mutant and original epitopes. ed side chains were structurally and functionally similar. This indicates that characteristics such as the charge, structure, hydrophilicity, and hydrophobicity of individual side chains of the epitope differently contribute to epitope-antibody binding.

For the 3H7 epitope, E487D, E487Q, 1488L, and 1488V showed highly decreased reactivity with the $3 \mathrm{H} 7$ antibody (Fig. 4B). These results indicate that E487 and 1488 are important in reactivity of the $3 \mathrm{H} 7$ epitope. E489D and E490D showed similar and/or increased responses, whereas their Gln mutants, $E 489 Q$ and $E 490 Q$, showed decreased responses with the $3 \mathrm{H} 7$ antibody. These results suggest that consecutive negative charges are critical for $3 \mathrm{H} 7$ epitope function.

Most single substitution mutations of 2B8 and $3 \mathrm{H} 7$ epitopes showed decreased or completely abolished epitope-antibody reactions. These results suggest that these epitope residues are important for reactivity. However some mutations showed increased response (Fig. 4A). The F8A mutation showed a roughly $30 \%$ increase in response (Fig. $3 A$ ). To determine whether a combination of mutations could reinforce the response, dual mutations were generated. As shown in Fig. 5A, however, dual mutations of D4E/F8A and D4E/F8Y did not show reinforced responses compared with single mutants, suggesting that each residue of the 2B8 epitope has its own role in the response. Taken together, these results indicate that the F8A mutated sequence (RDPLPAFPP) of the 2B8 epitope is a promising candidate for development of an improved 2B8 epitope tag.

The $3 \mathrm{H} 7$ epitope was also mutated by combining two single mutations in order to increase the response. Since E489A and E490D showed significant increases in response, the dual mutation E489A/E490D was generated for testing. As shown in Fig. $5 \mathrm{~B}$, dual mutation of the $3 \mathrm{H} 7$ epitope sequence reinforced about $30 \%$ of the response for the $3 \mathrm{H} 7$ antibody. This result strongly suggests that the new epitope sequence (PGEIAD) is a better epitope for the $3 \mathrm{H} 7$ antibody.

Usefulness of $2 B 8$ and $3 H 7$ epitopes and their mimotopes as tags

To investigate the usability of $2 \mathrm{~B} 8$ and $3 \mathrm{H} 7$ epitopes for protein detection compare with commercially available tags, Western blot analysis was carried out with commercial epitope tags, including His-, Myc-, and FLAG-tags, and 2B8 and $3 \mathrm{H} 7$ tags. The $2 \mathrm{~B} 8$ and $3 \mathrm{H} 7$ epitopes and their mimotopes showed specific and stronger interactions with their respective antibodies, comparable to widely used commercial epitope tagging systems (Fig. 6). In addition, the 2B8 epitope was detectable when it was inserted between two different epitope tags or protein tags, suggesting that it can be used as a linker peptide (Fig. 7).

\section{DISCUSSION}

Small peptide tags are very useful and important for detecting proteins when the target specific antibody is not available. In this study, we characterized and analyzed the epitope sequences for $\mathrm{mAb} 2 \mathrm{~B} 8$ and $3 \mathrm{H} 7$ using Western blot and indirect ELISA. In a previous study, we characterized the original epitopes for mAb 2B8 and 3H7, which are short linear peptides (Kim et al., 2014). The specific amino acid sequences of both epitopes were unique compared with the amino acid sequences of known proteins. In particular, the 2B8 epitope ${ }^{3}$ RDPLPFFPP ${ }^{11}$ was not found in any known available protein database. The unique nature of the 2B8 epitope will be beneficial for application in a heterologous epitope tag system.

To confirm whether original sequences are the best epitopes for $\mathrm{mAb} 2 \mathrm{~B} 8$ and $3 \mathrm{H} 7$, we further analyzed the reactivity of mutated epitope tag sequences. Any single deletion from either 


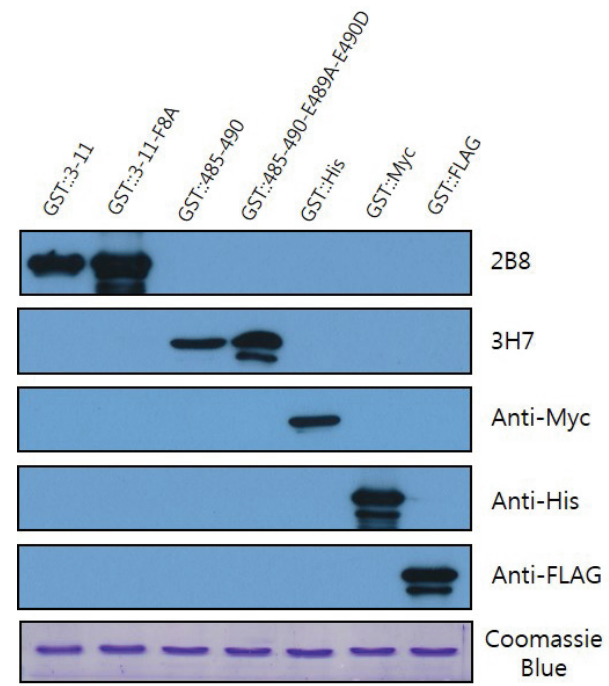

Fig. 6. Comparison of the reactivity of $2 \mathrm{~B} 8$ and $3 \mathrm{H} 7$ epitopes with those of commercial tags. 2B8 and $3 \mathrm{H} 7$ epitopes and commercial tags, such as Myc-, His-, and Flag-tags, were produced as GST fusion proteins. Reactivity of an individual epitope with its respective antibody was examined by Western blot.

the $\mathrm{N}$ - or C-terminal ends of the original nine- and six-amino acid epitope sequences ( ${ }^{3}$ RDPLPFFPP ${ }^{11}$ and ${ }^{485}$ PGEIEE $^{490}$ ) significantly decreased their binding affinities, suggesting that the original epitope sequences are minimally required (Fig. 1). In addition, any single deletion of an internal residue disrupting the original lengths also abolished responses, supporting the minimal length requirement (Fig. 2). Antibodies interact with a mimotope that is a different peptide sequence from the epitope with a similar functional property of side chains (Van Regenmortel, 1996). In many cases, the charge characteristics of side chains are essential for mimotope reactivity (Petersen et al., 2011).

A positive charge on the $2 \mathrm{~B} 8$ epitope is probably important for the response because Ala substitution of positively-charged Arg abolished the response (Fig. 3A). In addition, a positive charge with a guanidinium group was critical because substitution of R3 into Lys showed a significantly decreased response. In the case of $3 \mathrm{H} 7$, negative charges are critical for the response. Ala substitution of two negatively-charged Glu residues (E487 and E490) showed significantly decreased responses (Fig. 3B). A negative charge with the correct size is critical for E487 because substitutions into both a smaller negativelycharged Asp and a similarly sized neutral Gin nearly abolished the response (Fig. 4B). However, a negative charge itself was critical for E490 because E490D was more reactive than the original epitope, whereas $E 490 \mathrm{Q}$ showed highly decreased reactivity (Fig. 4B). A negative charge was also important for the 2B8 epitope. The effect of a negative charge on D4 was abolished when substituted into a similarly sized neutral Asn, whereas substitution into the similarly charged Glu maintained the response (Fig. 4A).

The hydrophobic effect was very important for the response. The hydrophobic side chains L6 in the 2B8 epitope and L488 in the $3 \mathrm{H} 7$ epitope were essential for responses of $2 \mathrm{~B} 8$ and $3 \mathrm{H} 7$ antibodies since substitution into lle or Val almost eliminated the responses (Fig. 4). The hydrophobic function of F9 was

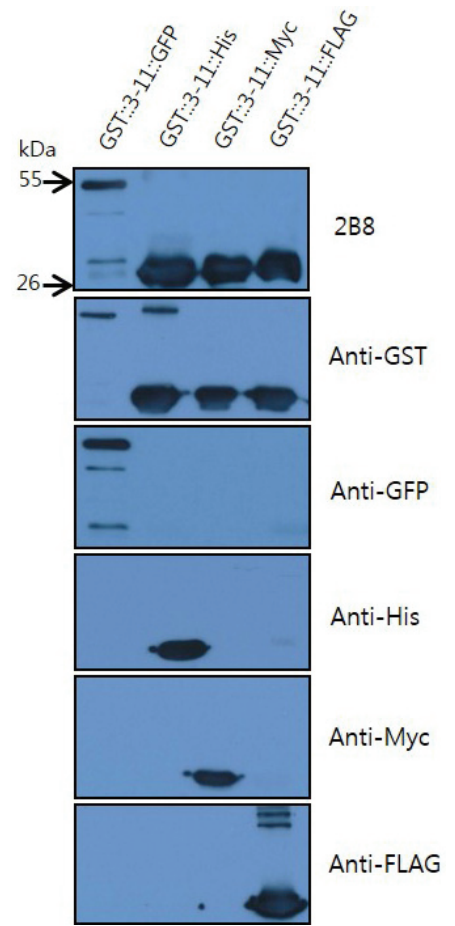

Fig. 7. Use of 2B8 epitope tags as linker peptides. The 2B8 epitope sequence was inserted between two different epitope or protein tags. Protein and epitope tags used were green fluorescence protein (GFP), GST, Myc-tag, His-tag, and Flag-tag. Reactivity of the 2B8 epitope as a linker peptide was analyzed by Western blot.

critical in the reactivity of the 2B8 epitope because substitution with Tyr significantly decreased the response, whereas mutation of F8 into Tyr showed no effect on epitope-antibody binding (Fig. 4A).

Antibody-antigen bindings are based on chemical interactions, including the ionic bonds, hydrophobic interactions, and hydrogen bonds. In this study, the charges and hydrophobic functions of epitopes were important for the responses of 2B8 and $3 \mathrm{H} 7$ antibodies. Most single substitutions of charged or hydrophobic residues significantly decreased the response. However, some substitutions increased responses, suggesting that the original 2B8 and $3 \mathrm{H} 7$ epitopes can be further optimized with enhanced reactivity to the respective antibody. Based on a series of single and dual substitutions, our results showed that the F8A substitution of $2 \mathrm{~B} 8$ and the E489A/E490D substitution of $3 \mathrm{H} 7$ were the best epitopes for responses of $2 \mathrm{~B} 8$ and $3 \mathrm{H} 7$ antibodies (Fig. 5). These results are important for developing new epitope tags because new substituted epitopes can have the advantages of increased responses with different charge and hydrophobicity. Users can select an epitope for their research needs because tagged epitopes can influence the solubility or structures of tagged target proteins.

Positive or negative charges are important for protein solubility and for biological function. Because charged residues can be involved in ionic and hydrogen bond formation, alterations of charged residues can change the secondary structures, tertiary structures, or ionic balance of proteins. Charged tags are advantageous in terms of solubility but can be disadvantageous for protein structure or biological function. Commercially availa- 
ble epitope tags are usually highly charged. Although the Histag is neutral at neutral $\mathrm{pH}$, it has six positive charges at a lower $\mathrm{pH}$ of 6.5. The Myc-tag (EQKLISEEDL) has four negative charges and one positive charge. FLAG-tag (DYKDDDDK) has five negative charges and two positive charges. The 2B8 and $3 \mathrm{H} 7$ epitopes analyzed in this study contained fewer charges but had sufficient solubility. The 2B8 epitope (RDPLPFFPP) has only one positive charge and one negative charge. The $3 \mathrm{H} 7$ epitope (PGEIEE) has three negative charges. However, the $3 \mathrm{H} 7$ substitution of E489A/E490D has two negative charges. The most important point of these epitopes was the uniqueness of the epitope sequences. The 2B8 epitope sequence ${ }^{3}$ RDPLPFFPP ${ }^{11}$ was not found in any known protein database based on BLAST search. This result suggests that this epitope can be used as a highly specific protein tag with low possibility of nonspecific recognition. With the $3 \mathrm{H} 7$ epitope, substituted mimotope PGEIAD showed a better response than the original sequence. This result demonstrates that new mutated tags can provide additional options in tag selection depending on the requirements of expressed target proteins.

All epitopes and mimotopes examined in this study were detected as both native and denatured conformations. In addition, the reactivity of these epitopes was as strong as those of widely used commercial epitope tagging systems (Fig. 6). Our findings strongly suggest that the $2 \mathrm{~B} 8$ and $3 \mathrm{H} 7$ epitopes and their mimotopes are valuable and useful new epitope tags for biochemical and analytic research fields.

Note: Supplementary information is available on the Molecules and Cells website (www.molcells.org).

\section{ACKNOWLEDGMENTS}

This work was supported by a grant from Kyung Hee University in 2015 (KHU-20150738).

\section{REFERENCES}

Bedouelle, H., and Duplay, P. (1988). Production in Escherichia coli and one-step purification of bifunctional hybrid proteins which bind maltose. Export of the Klenow polymerase into the periplasmic space. Eur. J. Biochem. 171, 541-549.

Bhoo, S.H., Davis, S.J., Walker, J., Karniol, B., and Vierstra, R.D. (2001). Bacteriophytochromes are photochromic histidine kinases using a biliverdin chromophore. Nature 414, 776-779.

Brizzard, B. (2008) Epitope tagging. Biotechniques 44, 693-695.

Bucher, M.H., Evdokimov, A.G., and Waugh, D.S. (2002). Differential effects of short affinity tags on the crystallization of Pyrococcus furiosus maltodextrin-binding protein. Acta. Crystallogr. D. Biol. Crystallogr. 58, 392-397.

Chant, A., Kraemer-Pecore, C.M., Watkin, R., and Kneale, G.G. (2005). Attachment of a histidine tag to the minimal zinc finger protein of the Aspergillus nidulans gene regulatory protein AreA causes a conformational change at the DNA-binding site. Protein Expr. Purif. 39, 152-159.

Cheng, H.W., Chen, K.C., Raja, J.A., Li, J.X., and Yeh, S.D. (2013). An efficient tag derived from the common epitope of tospoviral NSs proteins for monitoring recombinant proteins expressed in both bacterial and plant systems. J. Biotechnol. 164, 510-519.

Chu, H.Y., and Englund, J.A. (2013). Respiratory syncytial virus disease: prevention and treatment. Curr. Top Microbiol. Immunol. 372, 235-258

Davis, S.J., Vener, A.V., and Vierstra, R.D. (1999). Bacteriophytochromes: phytochrome-like photoreceptors from nonphotosynthetic eubacteria. Science 286, 2517-2520.

de Mello, R.A., Marques, A.M., and Araujo, A. (2013). HER2 therapies and gastric cancer: a step forward. World J. Gastroenterol. 19, 6165-6169.

Evan, G.I., Lewis, G.K., Ramsay, G., and Bishop, J.M. (1985). Isolation of monoclonal antibodies specific for human c-myc proto- oncogene product. Mol. Cell Biol. 5, 3610-3616.

Field, J., Nikawa, J., Broek, D., MacDonald, B., Rodgers, L., Wilson, I.A., Lerner, R.A., and Wigler, M. (1988). Purification of a RASresponsive adenylyl cyclase complex from Saccharomyces cerevisiae by use of an epitope addition method. Mol. Cell Biol. 8, 2159-2165

Gasic, K., and Korban, S. (2005). Nonspecific binding of monoclonal anti-FLAG M2 antibody in Indian mustard (Brassica juncea). Plant Mol. Biol. Rep. 23, 9-16.

Goel, A., Colcher, D., Koo, J.S., Booth, B.J., Pavlinkova, G., and Batra, S.K. (2000). Relative position of the hexahistidine tag effects binding properties of a tumor-associated single-chain Fv construct. Biochim. Biophys. Acta 1523, 13-20.

Hopp, T.P., Prickett, K.S., Price, V.L., Libby, R.T., March, C.J., Pat Cerretti, D., Urdal, D.L., and Conlon, P.J. (1988). A Short Polypeptide Marker Sequence Useful for Recombinant Protein Identification and Purification. Nat. Biotech. 6, 1204-1210.

Jarvik, J.W., and Telmer, C.A. (1998). Epitope tagging. Annu. Rev. Genet. 32, 601-618.

Kim, T.L., Yoo, J., Sangsawang, K., Cho, M.H., Yang, S.H., Suh, J.W., Hahn, T.R., and Bhoo, S.H. (2014). Epitope mapping of monoclonal antibodies for the Deinococcus radiodurans bacteriophytochome. Protein Sci. 23, 812-818.

Kolodziej, P.A., and Young, R.A. (1991). Epitope tagging and protein surveillance. Methods Enzymol. 194, 508-519.

Lopez-Requena, A., Burrone, O.R., and Cesco-Gaspere, M. (2012). Idiotypes as immunogens: facing the challenge of inducing strong therapeutic immune responses against the variable region of immunoglobulins. Front Oncol. 2, 159.

Martin-Mateos, M.A. (2007). Monoclonal antibodies in pediatrics: use in prevention and treatment. Allergol. Immunopathol. 35, 145-150.

Neill, J.D., Sellers, J.C., Musgrove, L.C., and Duck, L.W. (1997). Epitope-tagged gonadotropin-releasing hormone receptors heterologously-expressed in mammalian (COS-1) and insect (Sf9) cells. Mol. Cell. Endocrinol. 127, 143-154.

Nygren, P.A., Stahl, S., and Uhlen, M. (1994). Engineering proteins to facilitate bioprocessing. Trends Biotechnol. 12, 184-188.

Park, S.H., Cheong, C., Idoyaga, J., Kim, J.Y., Choi, J.H., Do, Y., Lee, H., Jo, J.H., Oh, Y.S., Im, W., et al. (2008). Generation and application of new rat monoclonal antibodies against synthetic FLAG and OLLAS tags for improved immunodetection. J. Immunol. Methods 331, 27-38.

Petersen, N.H., Hansen, P.R., and Houen, G. (2011). Fast and efficient characterization of an anti-gliadin monoclonal antibody epitope related to celiac disease using resin-bound peptides. J. Immunol. Methods 365, 174-182.

Porath, J., Carlsson, J., Olsson, I., and Belfrage, G. (1975). Metal chelate affinity chromatography, a new approach to protein fractionation. Nature 258, 598-599.

Routzahn, K.M., and Waugh, D.S. (2002). Differential effects of supplementary affinity tags on the solubility of MBP fusion proteins. J. Struct. Funct. Genomics 2, 83-92.

Sachdev, D., and Chirgwin, J.M. (1999). Properties of soluble fusions between mammalian aspartic proteinases and bacterial maltose-binding protein. J. Protein Chem. 18, 127-136.

Schmidt, T.G., and Skerra, A. (1993). The random peptide libraryassisted engineering of a C-terminal affinity peptide, useful for the detection and purification of a functional lg Fv fragment. Protein Eng. 6, 109-122.

Simmons, C.P., Bernasconi, N.L., Suguitan, A.L., Mills, K., Ward, J.M., Chau, N.V., Hien, T.T., Sallusto, F., Ha do, Q., Farrar, J., et al. (2007). Prophylactic and therapeutic efficacy of human monoclonal antibodies against H5N1 influenza. PLoS Med. 4, e178.

Smith, D.B., and Johnson, K.S. (1988). Single-step purification of polypeptides expressed in Escherichia coli as fusions with glutathione S-transferase. Gene 67, 31-40.

Smith, J.C., Derbyshire, R.B., Cook, E., Dunthorne, L., Viney, J. Brewer, S.J., Sassenfeld, H.M., and Bell, L.D. (1984). Chemical synthesis and cloning of a poly(arginine)-coding gene fragment designed to aid polypeptide purification. Gene 32, 321-327.

Sun, W.P., Wang, F.M., Xie, F., Wang, G.Q., Sun, J., Yu, G.H., Quu, Y.H., and Zhang, X.G. (2007). A novel anti-human syndecan-1 (CD138) monoclonal antibody 4B3: characterization and application. Cell Mol. Immunol. 4, 209-214.

Terpe, K. (2003). Overview of tag protein fusions: from molecular 
and biochemical fundamentals to commercial systems. Appl. Microbiol. Biotechnol. 60, 523-533.

Van Regenmortel, M.H.V. (1996). Mapping epitope structure and activity: from one-dimensional prediction to four-dimensional description of antigenic specificity. Methods 9, 465-472.

Waugh, D.S. (2005). Making the most of affinity tags. Trends Biotechnol. 23, 316-320.
Woestenenk, E.A., Hammarstrom, M., van den Berg, S., Hard, T., and Berglund, H. (2004). His tag effect on solubility of human proteins produced in Escherichia coli: a comparison between four expression vectors. J. Struct. Funct. Genomics 5, 217-229.

Wu, J., and Filutowicz, M. (1999). Hexahistidine (His6)-tag dependent protein dimerization: a cautionary tale. Acta Biochim. Pol. 46, 591-599. 